\title{
LOW BACK PAIN;
}

TRIGGER POINT INJECTIONS IN PATIENTS WITH LOW BACK PAIN.

1. MBBS, FCPS, FRCS Eng (SN), FEBNS

Assistant Professor

Department of Neurosurgery,

MTI-Lady Reading Hospital, Peshawar

2. MBBS, FCPS

Assistant Professor

Department of Neurosurgery,

MTI-Lady Reading Hospital, Peshawar.

3. MBBS

Resident

Department of Neurosurgery,

MTI-Lady Reading Hospital,

Peshawar

4. MBBS

Resident

Department of Neurosurgery,

MTI-Lady Reading Hospital,

Peshawar

Correspondence Address:

Dr. Bilan Khan

Department of Neurosurgery

Lady Reading Hospital, Peshawar.

bkafridi675@yahoo.com

Article received on:

02/08/2018

Accepted for publication:

26/11/2018

Received after proof reading:

$18 / 04 / 2019$

\begin{abstract}
Bilal Khan ${ }^{1}$, Khalid Khanzada ${ }^{2}$, Sajjad Ullah ${ }^{3}$, Usman Haqqani ${ }^{4}$
\end{abstract}
ABSTRACT... Objectives: To know about the efficacy of trigger point injections in low back pain. Study Design: Prospective observational study. Setting: Out-patient Department of Naseer Teaching Hospital, Peshawar, and private clinic of the author. Period: March 2016 to January 2017. Materials and Methods: All patients with low back pain were evaluated. Inclusion criteria was; all patients with low back pain greater than 3 months duration whether operated or not, patients with non-radiating symptoms, patients with acceptable radiology (no listhesis, obvious stenosis/disk, albeit some degree of degeneration was acceptable), further helping points were morning exacerbations and elicitation of tender spot by the patient. The exclusion criteria was Low back pain with less than 3 months duration, obvious pathology on radiological examination, radiating symptoms, generalized low back pain without any point tenderness elicitation. The patients were sent home on medications and asked to avoid strenuous activity for a couple of weeks, they were followed after one month and asked about their pain satisfaction. Results: Approximately 2800 patients were evaluated for low back pain and of them $237(8.46 \%)$ patients were upto the inclusion criteria, only 112 patients had agreed to have a TPI, which showed an acceptance rate of $47.25 \%$. There were 65 males and 58 females, with a male to female ratio approaching almost 1:1. The age range was from 18 to 48 years, and the mean age was 32 years. The minimum duration of pain was 3 months and the maximum duration was 4 years, 4 patients had undergone back surgery. Almost all patients pointed out the pain spot, but a typical trigger point was elicited in $58(51.78 \%)$ patients, while morning exacerbation was present in $43(38.38 \%)$. Radiological examination was performed on all patients in the form of simple xrays and Magnetic resonance imaging scans, it was acceptable in $67 \%$, as patients with radiating symptoms were already excluded. $10.71 \%(n=12)$ patients had some problems. Conclusion: In patients with chronic low back pain due to Myofascial Pain Syndrome (MPS) eliciting the trigger points by either elaboration through history or physical examination and treating them with a TP injection with lignocaine and a steroids has good short term results.

Key words: Injection, Low Back Pain, Trigger Point, Myofacisal Pain Syndrome, Radiculopathy, Efficacy.

Article Citation: Khan B, Khanzada K, Sajjad Ullah, Haqqani U. Low back pain; trigger point injections in patients with low back pain. Professional Med J 2019; 26(5):819-824. DOI: 10.29309/TPMJ/2019.26.05.3483

\section{INTRODUCTION}

Low Back pain is an extremely common condition, it is the most common cause of disability for persons $<45 \mathrm{yrs}$ age (15\% of all sick leave from work), estimates of lifetime prevalence range from $60-90 \%$, and the annual incidence is $5 \%{ }^{1}$ There are many causes of LBP, like mechanical and neurological, and among them one is myofascial pain syndrome-which originates from myofascial trigger points in skeletal muscle. It is also implicated in patients with headache, neck pain, and various other musculoskeletal/systemic disorders. ${ }^{2}$ Trigger points (TP) is an area of tenderness at rest or on palpation, a taut band of muscle, with a local twitch response, and cause referred pain elicited by firm compression. The prevalence of myofascial trigger points among patients complaining of pain anywhere in the body ranged from $30 \%$ to $93 \% .^{3}$ The pathogenesis of TPs is unclear but theories implicate that tissue ischemia resulting from prolonged muscle contraction with accumulation of acids and chemicals such as serotonin, histamine, kinins. These changes are fed into a cycle of increasing motor or sympathetic activity and can lead to increased pain. Patients with myofascial pain 
syndrome due to trigger points usually have a chronic pain, and can lead to several days off work. ${ }^{4,5}$ Many modalities have been used to alleviate pain originating from trigger points and includes mechanical stimulation, physiotherapy, ultrasound stimulation, and injection of the trigger point with distilled water, steroids, local anaesthetic or local anaesthetic and steroids combined, with promising results..$^{6,7}$

Since in our society manual work and long hours of sitting is a common practice, predisposing to various mechanical low back pain, including MPS due to TPs, we conducted this study to know about the efficacy of injecting the TPs with local anaesthetics and steroids.

\section{MATERIALS AND METHODS}

This study was conducted in the out-patient department of Naseer Teaching Hospital, Peshawar, and private clinic of the author between March 2016 to January 2017. All patients with low back pain were evaluated. Inclusion criteria was; all patients with low back pain greater than 3 months duration whether operated or not, patients with non radiating symptoms, patients with acceptable radiology (no listhesis, obvious stenosis/disk, albeit some degree of degeneration was acceptable), further helping points were morning exacerbations and elicitation of tender spot by the patient. The exclusion criteria was Low back pain with less than 3 months duration, obvious pathology on radiological examination, radiating symptoms, generalized low back pain without any point tenderness elicitation. Patients were pre-counseled about the injection into the area of intense pain-steroids plus local anesthetic, on a 24G needle and were placed in sitting position with back towards the physician, they were asked to localize the area of intense pain with fingers, and further asked to bend a bit forward to make the muscles more obvious, area was then prepped with alcohol swab. Patients were further asked to put their arms on their knees, needle was inserted into the skin, subcutaneous tissue and fascia, with a pop up feeling. Medication were injected in small aliquots of $0.3 \mathrm{cc}$, negative suction was maintained throughout to avoid injections into a blood vessel, they were placed in supine position for a couple of minutes to alleviate the painful effects of injections and avoid any dizziness reported with local anesthetic. The patients were sent home on medications and asked to avoid strenuous activity for a couple of weeks, they were followed after one month and asked about their pain satisfaction.

\section{RESULTS}

Approximately 2800 patients were evaluated for low back pain and of them 237 (8.46\%) patients were upto the inclusion criteria, only 112 patients had agreed to have a TPI, which showed an acceptance rate of $47.25 \%$. There were 65 males and 58 females, with a male to female ratio approaching almost 1:1. The age range was from 18 to 48 years, and the mean age was 32 years. the minimum duration of pain was 3 months and the maximum duration was 4 years, 4 patients had undergone back surgery. Almost all patients pointed out the pain spot, but a typical trigger point was elicited in 58(51.78\%) patients, while morning exacerbation was present in 43(38.38\%) as shown in Figure-1 and 2.

Radiological examination was performed on all patients in the form of simple xrays and Magnetic resonance imaging scans, it was acceptable in $67 \%$, as patients with radiating symptoms were already excluded. $10.71 \%(n=12)$ patients had some problems with the injections like dizziness, vertigo and pain at injection sites, as shown in Figure-2.

10 patients were lost to follow up and 83(81.37\%) patients of the remaining had improvement in symptoms, Figure-4.

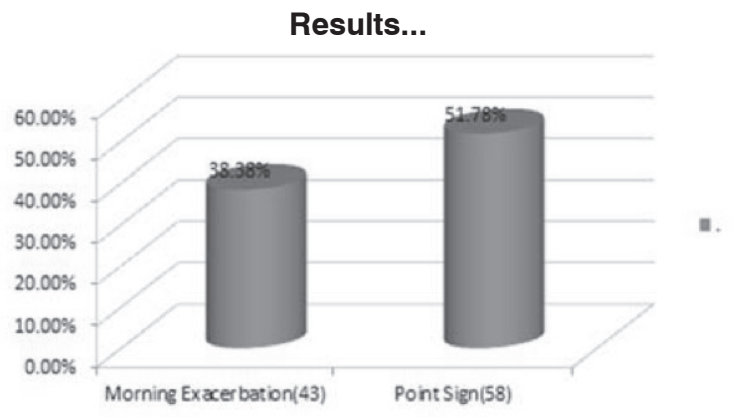

Figure-1. The above chart data shows the number of patients having a characteristic of their low back pain and their relative percentage. 
Side Effects Profile

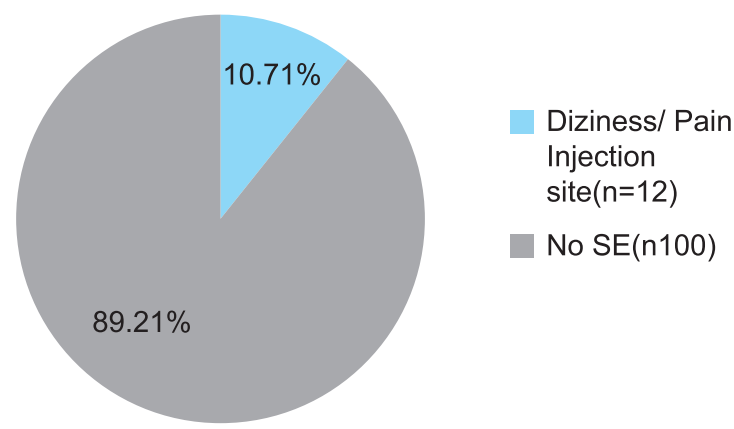

Figure-2. Shows the side effects of medications at the trigger point, almost $11 \%$ of the patients had problems with the TPI in the form of dizziness, vertigo and pain at the site of injection for almost three days.

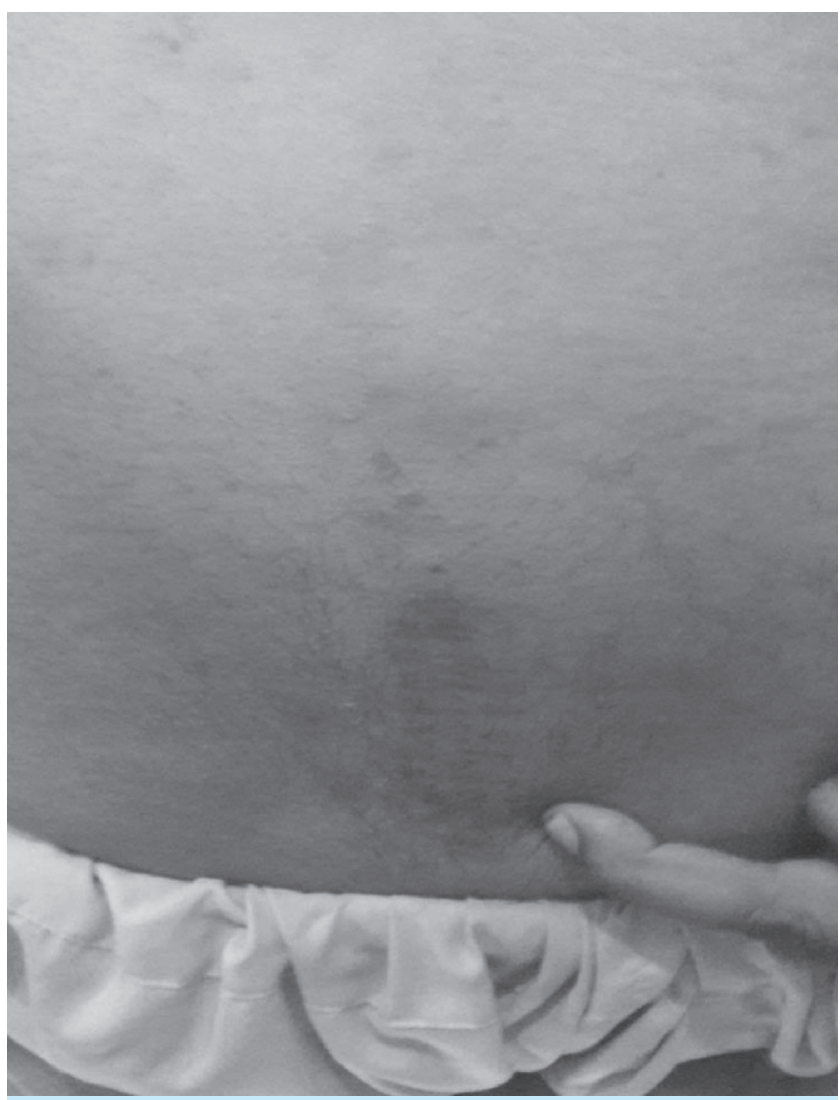

Figure-3. A patient eliciting a trigger point, the post operative scar can be seen in the midline.

\section{DISCUSSION}

Trigger points are implicated as the underlying cause of many pain syndromes, particularly the myopfascial pain syndrome (MPS), an established cause of low back pain.

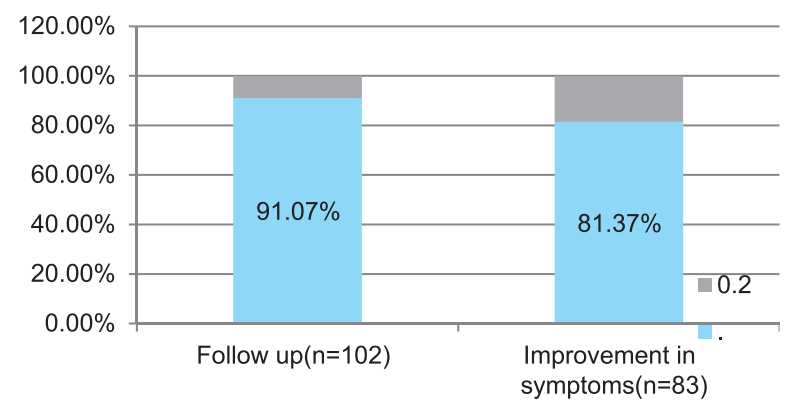

Figure-4. Shows the follow up of patients and the percent of patients that showed improvement in the symptomatology, as can be seen, the overall satisfaction rate was $81.37 \%$.

While modalities used for low back pain ranges from the most simple as massage and physiotherapy to lumbar spine surgery and instrumentation in the form of transpedicular fixation, Transforaminal and posterior Lumbar Interbody Fusion (TLIF and PLIF respectively); we assesed the efficacy of trigger point injections in a specific subset of patient with low back pain. ${ }^{8,9}$ There are various ways to identify a trigger point and treat them i.e. physician's sense of feel/ patient expressions of pain upon palpation are the most commonly used method to localize a trigger point. Physical finding is palpation of a hypersensitive bundle of muscle fibre of harder than normal consistency. ${ }^{6}$

Only $8.46 \%$ of all the patients evaluated during the study period came out to be having a myofascial pain syndrome, filling up the criteria to be eligible for an injection. The male to female ratio was approaching to 1.2:1. However, the sex ratio is almost similar in most countries around the globe. In our society they perform activities of daily living, like cleaning the house, brawling the food, and washing clothes, which require a posture putting pressure on the lumbar spine, while man work mostly in the offices-which required long term sitting, or were labourers doing manual jobs. These are all risk factors for LBP and also includes heavy lifting and twisting, bodily vibration, obesity, and poor conditioning, although low back pain is also common even in people without these risk factors. ${ }^{10}$

The mean age in our study was 32 years, and 
it range from 18 to 48 years. As stated earlier, men were mostly labourers and the female we attended were mostly housewives, and this has been the peak age for both genders in our society to be very active physically. Worldwide the mean age affecting the population with low back pain is usually young. A study on young individuals in India aged 18-35 years showed that the highest prevalence is among those between 20-30 years of age and this has also been reported in the studies from the western countries. It is believed that adults of working age group are the most vulnerable to low back pain, and hence that the prevalence of back pain decreases around the middle of the sixth decade. ${ }^{11-13}$

The minimum duration of symptoms was 03 years and the maximum duration was 04 years. We did not enlist any patient with less than 03 months of symptoms including any patients with an acute lumbar sprain. As any pain less than 03 months duration is deemed as acute low back pain and most of the times resolves without any intervention in $95 \%$ of cases, and only a minority has chronic LBP i.e. duration greater than 03 months. ${ }^{14}$

Trigger points in the form of taut muscle band and slight tender on palpation was found in 58 $(51.78 \%)$ patients. The rest of the patients had a location very specific for the TPs, as specified by the Travel and Simons, almost all of the patients elicited a point sign-pointing out the area of intense pain at the lower back, at the origin of Gluteus medius or the insertion of the quadratus lumborum ${ }^{15}$, as depicted in the Figure-3. The pain was aggravated with the movement of the body or bending forward, they correlated it to the heavy lifting or prolonged sitting. The proposed mechanism for the trigger point is said to be related to tissue ischemia resulting from prolonged muscle contraction with accumulation of acids and chemicals such as serotonin, histamine, kinins. These changes are fed into a cycle of increasing motor or sympathetic activity and can lead to increased pain even to minor stimuli. As said its either Physician's sense of feel or patient expressions of pain upon palpation to localize a trigger point. Physical finding of a TP is palpation of a hypersensitive bundle of muscle fiber of harder than normal consistency. ${ }^{5,6}$

Hong reported that, "either lidocaine injection or dry needling of trigger points, the patients experienced almost complete relief of pain immediately after injection if local twitch responses were elicited. On the other hand, they experienced only minimal relief if no such response occurred during injection". ${ }^{15} \mathrm{Immediate}$ pain relief upon injection portended a good outcome in our patients.

Morning exacerbation was present in $38.38 \%$ of patients and it correlated with the type of pain that is present. Some of the patient reported pain while getting up from the bed early in the morning and side rolling while asleep. Radiology was acceptable in $67 \%$ of patients. By acceptable radiology we meant Xrays, CT and MR scans of the lumber spine which does not show any obvious deformity like listhesis, ruptured disc, fractured vertebra, very narrow stenosis and tumors etc. However if a patient reported LBP and he does have an incidental findings of lumber stenosis it was also taken as acceptable radiology. Thomas $\mathrm{B}^{17}$, reported that in $30 \%$ cases, listhesis was an incidental finding, and the cause of symptoms was non-specific low back pain. As noted earlier, since radiating symptoms were already excluded so even a prolapsed disc was considered as incidental finding in these patients.

Some patients $(10.71 \%, \mathrm{n}=12)$ patients had problems with the injections like dizziness, vertigo and pain at injection site. In a review by the Cochrane database 9 out of eighteen studies showed side effects like side effects such as headache, dizziness, transient local pain; however tingling and numbness and nausea were reported in small numbers of patients. ${ }^{18}$

As stated earlier earlier, 10 patients were lost to follow up and among the remaining, 83 (81.37\%) patients had improvement in symptoms. Thomas $B$ reported that making a specific diagnosis yield excellent or good results in $83 \%$ of cases among low back pain patients. ${ }^{17}$ Although Cochrane review does not endorse the long term efficacy of 
injection therapy in the form of epidural steroids, facet joint injections and trigger point injections, however they do support a specific type of therapy for a specific low back pain. ${ }^{18}$ Since we mainly focused on the main characteristics like history of muscle sprain, unilaterlality and pointing out a tender spot by the patient or feeling by the clinician, all of which narrowed the disease spectrum to myofascial low back pain, we concluded that in such patients TPIs are efficient in the short term, yet to see a long term result which is quite difficult to follow in our set up; and it was one of the short comings of our study.

\section{CONCLUSION}

In patients with chronic low back pain due to Myofascial Pain Syndrome (MPS) eliciting the trigger points by either elaboration through history or physical examination and treating them with a TP injection with lignocaine and a steroids has good short term results. Also patient selection is the most important factor, and in selected patient population, TPI has good results.

Copyright(C) 26 Nov, 2018.

\section{REFERENCES}

1. Cypress B K: Characteristics of physician visits for back symptoms: A national perspective. Am J Public Health 73: 389-95, 1983.

2. Han SC, Harrison P. Myofascial pain syndrome and trigger-point management. Regional Anesthesia. 1997; 22(1):89-101.

3. Garvey TA, Marks MR, Wiesel SW. A prospective, randomized, double-blind evaluation of trigger-point injection therapy for low-back pain. Spine. 1989; $14(9): 962-9$.

4. Simons D, Travell J, Simons L. Travell \& Simons' Myofascial Pain and Dysfunction: The Trigger Point Manual. 2nd edition. Baltimore, Md, USA: Williams \& Wilkins; 1999.

5. Simons DG. Clinical and etiological update of myofascial pain from trigger points. Journal of Musculoskeletal Pain. 1996; 4(1-2):93-121.

6. Travel J, Rinzler SH. The myofascial genesis of pain. Postgraduate Medicine. 1952; 11(5):425-34.
7. Hong CZ. Lidocaine injection versus dry needling to myofascial trigger point: The importance of the local twitch response. American Journal of Physical Medicine and Rehabilitation. 1994; 73(4):256-263.

8. Greenberg MS. Handbook of Neurosurgery. Eighth edition, New York, Theime:2016.

9. Yavin D, Casha S, Wiebe S, Feasby TF, Clark C. Lumbar fusion for degenerative disease: A Systematic review and meta-analysis. Neurosurgery 2017; 80(5):701-15.

10. Andersson GBJ. The epidemiology of spinal disorders. In: Frymoyer JW, ed. The adult spine: principles and practice. 2nd ed. Philadelphia: Lippincott-Raven, 1997:93-141.

11. Walker BF. The prevalence of low back pain: A systematic review of the literature from 1966 to 1998. J Spinal Dis 2000; 13: 205-17.

12. Leboeuf-Yde C, Lauritsen JM. The prevalence of lowback pain in the literature - a structured review of 26 nordic studies from 1954 to 1993. Spine 1995; 20: 2112-8.

13. Bressler HB, Keyes WJ, Rochon PA, Badley E. The prevalence of low back pain in the elderly - A systematic review of the literature. Spine 1999; 24: 1813-9.

14. Carey TS, Garrett J, Jackman A, McLaughlin C, Fryer $\mathrm{J}$, Smucker DR. The out-comes and costs of care for acute low back pain among patients seen by primary care practitioners, chiropractors, and orthopedic surgeons: the North Carolina Back Pain Project. N Engl J Med. 1995; 333(14):913-917.

15. Njoo KH, Does V. The occurrence and inter-rater reliability of my ofascial trigger points in the $\sim$ uadratus lumborum and gluteus medius: A prospective study in non-specific low back pain patients and controls in general practice. Pain, 58 (1994) 3 17-23.

16. Hong $C Z$. Lidocaine injection versus dry needling to myofascial trigger point: The importance of the local twitch response. American Journal of Physical Medicine and Rehabilitation. 1994; 73(4):256-63.

17. Thomas $B$, Willis $\mathrm{K}$, William $\mathrm{H}$. Recognizing specific characteristics of non specific low bak pain. Clinical ortho and related research. April 1987; 331-9.

18. http://journals.lww.com/spinejournal/ Abstract/2009/01010/Injection_Therapy_for_Subacute_ and_Chronic_Low.10.aspx. 


\title{
It's only after we've lost everything that we're free to do anything.
}

\author{
"Tyler Durden"
}

\section{AUTHORSHIP AND CONTRIBUTION DECLARATION}

\begin{tabular}{|c|c|c|c|}
\hline Sr. \# & Author-s Full Name & Contribution to the paper & Author $=\mathbf{s}$ Signature \\
\hline 1 & Bilal Khan & $\begin{array}{l}\text { Conceived the idea, data } \\
\text { collection, review of literature. }\end{array}$ & \\
\hline 2 & Khalid Khanzada & $\begin{array}{l}\text { Data collection, review of } \\
\text { literature. }\end{array}$ & d \\
\hline 3 & Sajjad Ullah & $\begin{array}{l}\text { Data collection review of } \\
\text { literature, analysis of data. }\end{array}$ & \\
\hline 4 & Usman Haqqani & $\begin{array}{l}\text { Data collection, review of } \\
\text { literature, analysis of data. }\end{array}$ & $b$ \\
\hline
\end{tabular}

